\title{
Opportunities, Challenges and Creative Teaching Practices of New International and Local Recruits in Hong Kong
}

\author{
By Paula Hodgson*
}

\begin{abstract}
Internationalization in higher education in Hong Kong has brought many enriched learning opportunities for students, because international recruits create an alternative learning culture that embraces global perspectives and international research to the curriculum. However, those new to teaching and with non-Asian backgrounds may experience a steeper learning curve as they adjust to a new culture, systems and expectations while working in Hong Kong. Of about $80 \%$ local students, educators need to find creative strategies to facilitate them to have interactions and collaborations with nonlocal students, $15 \%$ of whom are from mainland China and have different learning habits. In addition, they have to manage teaching undergraduate and postgraduate programs, which have students from diverse knowledge and working experiences. Twenty-five recruits from social sciences and humanities participated in the study and their reflections on their teaching experiences were analysed using NVivo 11. Solutions on meeting the challenges, good teaching practice and unresolved issues are discussed.
\end{abstract}

Keywords: higher education, inclusive teaching, International academics, new recruits, pedagogy

\section{Introduction}

"Hong Kong as an education hub" was cited in the University Grants Committee report (2010), and a forecast that "Asia will constitute about $70 \%$ of the global demand for higher education" in 2025 was also in the report (p. 55). There has been an ongoing strategy of recruiting international and mainland staff while promoting a good mix of international and local students in various programs in universities in the past two decades in Hong Kong (Lo \& Ng, 2013; Lee, 2014). At the same time, internationalization means learning English (Choi, 2010), because many university students have had Chinese as the medium of instruction in school as part of the academic adaptation (Yu \& Wright, 2017). The new four-year curriculum emphasizes an outcome-based education, and this has elicited many changes to the curriculum in both content and structure by local universities, including strategies on broadening science and arts education, bridging co-curricular activities, and outcome-based assessment to match international standards (Lanford, 2016). Despite the American style of liberation arts education being adopted at undergraduate level, many international staff have been recruited with new courses that were designed during the educational reform. This paper presents a study of new recruits to a local university in Hong Kong.

"Professional Consultant, the Chinese University of Hong Kong, Hong Kong. 
New recruits may mean new to university teaching, new to teaching in Hong Kong but with a few years of teaching in university in other part of the world, or new to teaching in this university but have experience of teaching in Hong Kong. To acquire proficiency in university teaching, new recruits may start from their own learning experience as students. However, to educate 21 st-century learners, they need to create a learning environment that focuses on student thinking and learning because they are living in an ever-changing world (Whitcomb, Borko, \& Liston, 2009). In preparing for new recruits in the changing educational landscape, the central unit that provides the orientation and emerging pedagogies play a significant role in building both staff capacity to adapt in their transition to working in a new environment and have opportunities to reflect on effective pedagogies that invite inclusivity in the context of Hong Kong. This paper will discuss the outcomes of the dialogical approach with new recruits on formulating effective teaching practices in a university in Hong Kong.

\section{New International Academics}

The global higher education ranking system has a major influence on the promotion of internationalization in higher education, including mobility of students and teachers (Knight, 2013). This is because international staff can raise the international publication portfolios (Maringe \& Sing, 2014). Educators have had a lot more opportunities to teach outside their home countries because globalization of higher education promotes international recruitment around the world, and many have experienced an initial adjustment phase (Jackson, 2008). There is a good assumption that new recruits know what academic life is and how to make a commitment to teaching and research and not anticipating any cultural shock (Foote, Wei, Monk, \& Theobold, 2008). After arrival, new recruits will experience a period of re-establishment of a new identity through in-department and central support while experiencing the professional adjustments (Green \& Myatt, 2011). This includes ways of living in a new country and various departmental and institutional practices, and some recruits may experience a steep learning curve even though academic sharing is a common goal when pursuing teaching and research excellence (Thomas \& Malau-Aduli, 2013). Moving into a totally new teaching environment, new recruits need to adapt to differences in academic standards, grading systems and expectations of students on studentteacher relationships and their behavior in class (Phillips, Harris, Larson, \& Higgins, 2009). They may be assigned to teach new subjects, to conduct mass lectures with a teaching lectern and be familiar with learning management systems. Nevertheless, internationalization is "the process of integrating an international, intercultural or global dimension into the purpose, functions or delivery of postsecondary education" (Knight, 2015, p. 3). Internationalization of the curriculum has created many opportunities for redesign and infusion of the new dimension of interdisciplinary, inclusive nature of multiculturalism. It is not merely what content is renewed, but how it is taught (De Vita \& Case, 2003; Robson \& Turner, 2007). This brings forth a test on a teacher's ability to teach in a 
different culture (Hathaway, 2018) and deploy a variety of learning and assessment tasks that can embrace inclusivity (Maringe \& Sing, 2014). Unsurprisingly, these teachers experience a heavy workload in which they have to make extra efforts in preparation but with very limited teaching experience (Green \& Myatt, 2011).

\section{Methodology}

To cultivate a high-quality, trusting relationship, the author adopted a dialogic approach when having discussions with individual new recruits, because this could cultivate an openness as if having collegial communication through respectful listening and a sense of sharing (Gergen, McNamee, \& Barrett, 2001; Shotter, 2006). The one-off, one-on-one engagement with new recruits offers collegial and intellectual discussion (Beech, Macintosh, \& Maclean, 2010). An informal meeting was arranged with each participant, and there were some common questions on teaching and learning, including (1) when the staff member has started serving in the university, (2) the types of courses that the staff member taught, and (3) different ways of teaching with undergraduates and postgraduates that the staff adopted. While paying attention to their teaching approaches, the author made observations on expression of the challenges experienced. After the informal discussion, these staff would reflect on the discussion and make a reflection on their teaching and thoughts generated. Their reflections were used for analysis in this paper. Four themes emerged: opportunities, challenges, solutions and good practice after the reflections were coded with NVivo11.

Twenty-five new recruits from social sciences and arts and humanities were invited to participate in the study. There were five from Hong Kong (20\%), eight from China (32\%), eight from Asia (three from Korea, three from Taiwan, one from Japan, one from Vietnam; 32\%), three from Europe (one from the United Kingdom, one from Spain, one from Sweden; 12\%) and one from the United States of America (4\%) (Table 1). However, many of them obtained their highest qualifications overseas as shown in Table 2: six graduated in Hong Kong (24\%), five in Europe (three from the United Kingdom, one from Spain, one from Sweden; 20\%) and 14 in the United States of America (56\%). This means that $76 \%$ of new recruits have had international research and education experiences. Twenty-two of them were hired in the research track and three in the teaching track. Despite their employment records, all of them had teaching responsibilities. Names of the participants were replaced with pseudonyms in the Findings and Discussion section. 
Table 1. Nationality of New Recruits

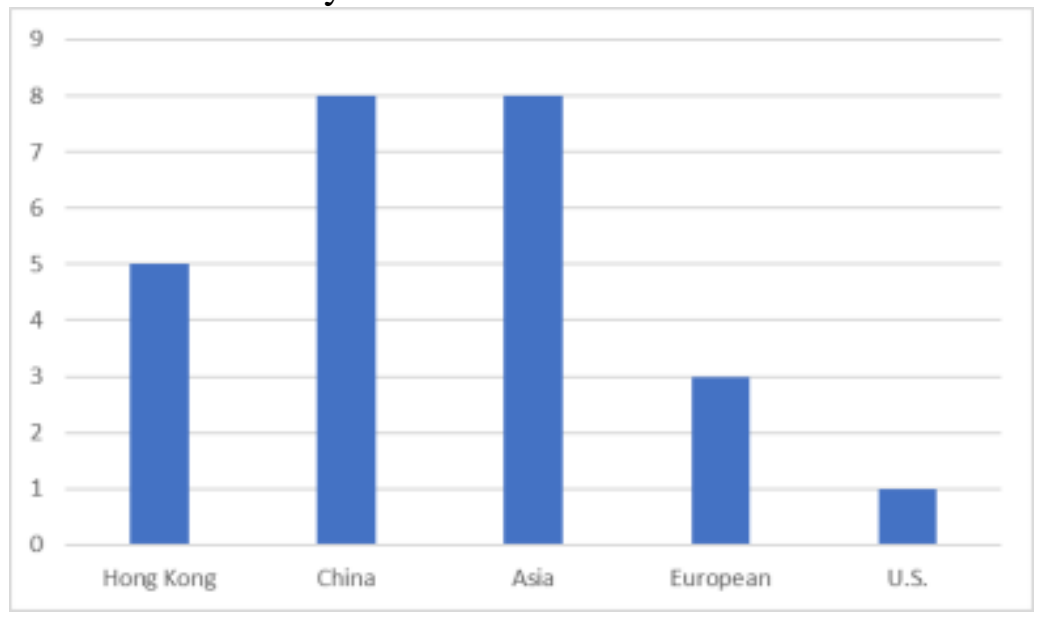

Table 2. Highest Qualification of New Recruits

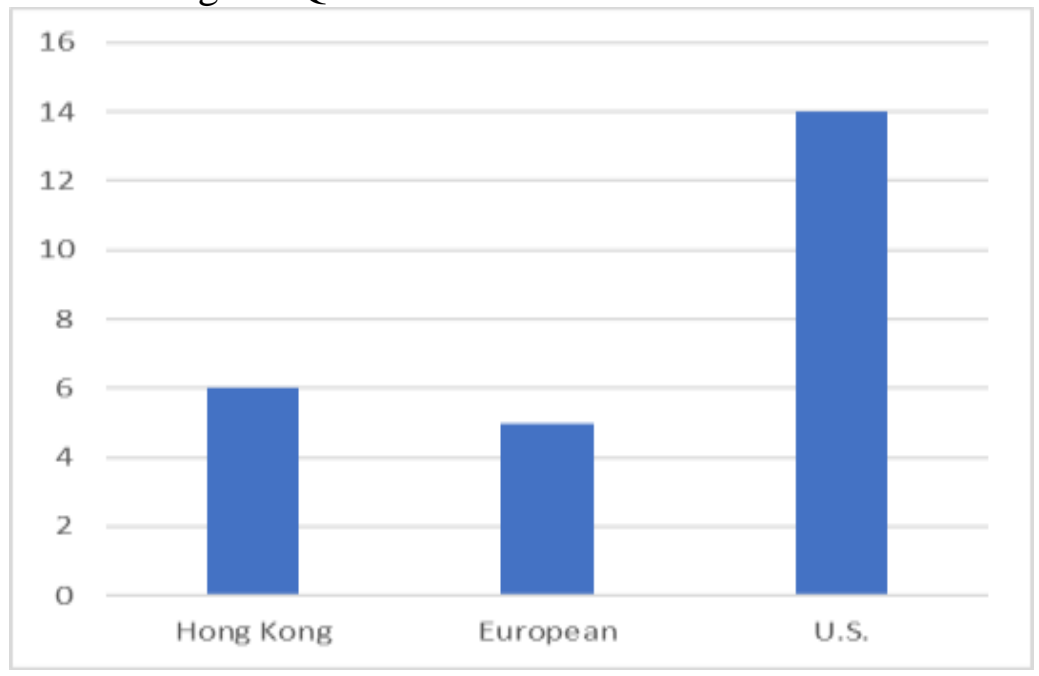

Findings and Discussion

Of the 25 new recruits, the majority obtained their highest research qualification from the United States of America. Thirteen were new to university teaching; nine had overseas teaching experience but would be unfamiliar with Chinese culture. Nevertheless, three of them had taught in other universities in Hong Kong and were very familiar with the learning behaviour of students in Hong Kong. In the reflection, there were many indicators that diversity of educational background, teaching and research experiences of these new recruits brought a rich teaching environment to the university. In the following, enriched learning opportunities, good practice, challenges and solutions were discussed.

\section{Enriched Learning Opportunities}

New international recruits have brought many new opportunities to local 
students because of their personal overseas education and research experiences. More importantly, future graduates will be well prepared for their international graduate destination, given the variety of international teaching strategies experienced in class (Stone, 2006).

- "I start the first class with small-group and/or whole-class activities (e.g., sharing students' (and my) background and culture) to help students get acquainted, and build a sense of community with trust" [T11, social work].

- "I personally like a symposium-like teaching style: I prefer to provide guidelines to students; inspire them to brainstorm and discuss, before I step in to give them more concrete suggestions as to how to put the ideas into action (for research or application)" [T12, sociology].

- "I divide students into peer groups hoping they can help each other by reading each other's work from the first to final stage" [T14, gender studies].

- "Integrating photography with social media in student assignment...a creative process focused on the ability to generate ideas that are both innovative and functional...'rooftop debate' became a pleasant habit in my class" [T25, architecture].

Internationalization of the curriculum means that there is an international dimension to degree programs. More importantly, there is a need to help students to gain a global perspective and open-mindedness as global citizens. This means that they are exposed to an international focus and have had opportunities to develop intercultural competence through interaction with international staff and students on campus (Soria \& Troisi, 2014) and the possibility of attending international events.

- "Having social work education and practice experiences in multiple countries/areas, I often use cases in different cultures and backgrounds as examples to enrich students' knowledge of human diversity" [T9, social work].

- "The topics range from glass ceiling in North America, foreign brides in Taiwan, domestic workers in Hong Kong, reproduction and parenthood in North Europe, manga and anime in Japan, beauty economy and sex work in China, and tied migration in US" [T17, gender studies].

- "A critical principle of my teaching was cultivating in students a global perspective and provide them an opportunity to reconsider their ingrained beliefs and perspectives... mostly used U.S. or Korean cases as example...I assigned a number of readings written by Western scholars" [T2, journalism and communication].

- "In the international monetary economics course, I take time to discuss the fragility of the Bretton Woods system, as well as the parallel between the 2001 Argentine crisis and the 2010 Greek crisis" [T3, economics].

- "An international collaborative event 'Learning from Barcelona' having field studies with a design exercise has become very popular. Students 
discover the city of Barcelona through thematic field trips. These 'itinerant lessons' are guided by prominent Barcelona historians, designers and planners" [T25, architecture].

New recruits have created many enriched learning possibilities through a variety of teaching strategies and approaches while maximizing engagement with students intellectually, broadening their horizons and meeting their needs. However, this does not undermine them when facing challenges. To those who have had experience of teaching in Hong Kong, they still need to adapt to a new teaching environment in a different university. For those new to teaching and with non-Asian backgrounds, they may experience a steeper learning curve as they adjust to a new culture, systems and expectations while working in Hong Kong.

\section{Challenges}

The student population is predominantly local in Hong Kong universities. Table 3 shows the population of undergraduates, taught postgraduates and research postgraduates in 2017-18. The challenge for new international recruits is about student language proficiency, because many of them were educated in schools with Chinese as the medium of instruction, and they commonly experience difficulty in acquiring proficiency in English to comprehend disciplinary-based learning, producing academic writing with appropriate styles and standards (Evans \& Morrison, 2011; Maringe \& Jenkins, 2015).

\section{Table 3. Student Population 2017-18}

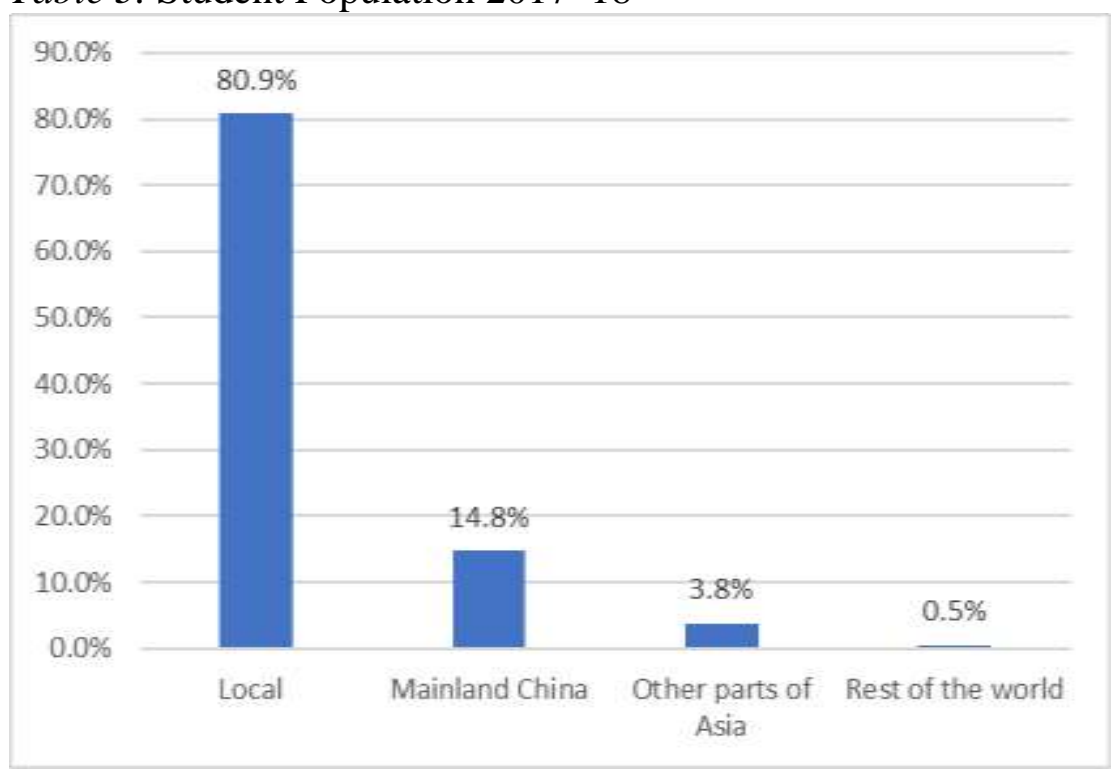

Diverse learning habits. Chinese learners have some common characteristics, such as being passive, and being reluctant to engage in critical thinking, argument and discussion. They regard teachers as authority figures but may be more dependent on them as mentors or pastoral counsellors who provide support and moral guidance (Gao \& Watkins, 2002). Generally, they do not prefer participatory 
modes of learning, particularly those less successful groups (Robson \& Turner, 2007), and this may be due to a variety of reasons, including a lack of required language proficiency, motivation and avoidance of embarrassment (Cheng, 2000). Nevertheless, undergraduates show a tendency to depend on educators (Gan, 2009).

Around $76 \%$ of new recruits have had education and research experience abroad but have very limited knowledge of the student learning culture in Hong Kong. Those who have taught in the USA note that Hong Kong students seem relatively passive, are good at copying teacher's work to their notebooks, and are reluctant to share their ideas or opinions in class. However, some students would prefer to approach their teachers at break time or at the end of a class. Some students may have difficulty to connect theories and real-world practice, but they often highlight this in their PowerPoint slides in preparation for examination. Hong Kong students tend to finish group assignments before the deadline for submission but spend less preparation time compared with mainland China students. They may not express their satisfaction or dissatisfaction directly to their teachers, but they make comments on teaching evaluation at the end of all courses.

On the other hand, mainland China students come to study in Hong Kong because scholarships are available, the world ranking and reputation of universities in Hong Kong is high, and it is convenient to go back to China for Chinese festivals; and they perceive the importance of acquiring international qualifications (Li \& Bray, 2007). Moreover, they expect educators to deliver content and transfer information in the way of teaching in China (Tavakol \& Dennick, 2010). Nevertheless, they exercise self-managed individual learning after class as a habit in preparation for achieving a pass in the language proficiency test, which is nationwide and is compulsory (Gan, 2009). Mainland China students are perceived as non-local students even though they share the same cultural background; it is because the educational experiences of mainland China students are very different from those in Hong Kong. Many mainland students like studying by themselves. They often sit in the front of a class, prepare their assignments well before deadlines and pay high attention to detail in their work. Language proficiency varies among mainland China students, some of whom can speak as fluently as a native while others can barely pronounce English words correctly (Hodgson, Lam \& Chau, 2011).

The learning habits of home students may be different from non-local students, and this can bring challenges to teachers to enable a congenial learning environment (Robson \& Turner, 2007). This means that Hong Kong students and mainland China students do not normally group together in group discussions or in group projects and assignments. Teachers may consider ways to mix them collectively in class activities and assessment tasks.

Teaching undergraduates and postgraduates. New recruits may have to teach both undergraduates and postgraduates in the university. However, one teacher noted that "I unrealistically asked students to reflect on traditional research methods in social science from the angle of feminist epistemology that I taught in my postgraduate class" [T17, gender studies]. Undergraduates find the content too 
advanced for them. Differentiation of learning challenges between undergraduates and postgraduates may seem obvious. However, research-tracked recruits comment that the gap in prior knowledge among learners in a master program is often large because those programs do not require students to have a prior undergraduate qualification. It is not uncommon to have a part-time master program with some students having years of professional working experience while others are new to the discipline but are aiming to acquire a master qualification.

\section{Solutions}

Addressing challenges in teaching in a university, educators need to focus on the needs of both local and non-local students. Local students expect teachers to be good moral models, warm-hearted and friendly, while non-local students expect their teachers to set interesting learning experiences (Walker \& Dimmock, 2000). They need to have strategies to assist learners with different expectations.

Teaching and learning. Among an abundance of teaching methods, the use of real-world problems is one of the best methods to enable students to build critical-thinking skills while learning to solve problems (Halpern, 1999; Dwyer, Hogan, \& Stewart, 2014). It is particularly important to expose students in undergraduate programs to such problems because they lack knowledge and hands-on skills at first, but they will need such skills in the real world. Moreover, educators play a central role not only in the cognitive domain but also in building a rapport with students and subsequently higher engagement with students, producing improved academic performance (Klem \& Connell, 2004) whereas various student community activities can contribute to personal growth (Strayhorn, 2008).

- "Choose simple real-world examples" [T19, economics].

- "Connect concepts with real-life situations and real-life experience" [T15, nursing].

- "The design thinking process invites students to frame the puzzle or the problem as a mystery, involving the students more creatively in the problem-solving process" [T5, Centre for China Studies].

- "Enhancing students' motivation to learn through actively involving students in the learning process and creating a supportive learning environment" [T9, social work].

- "Education as a means to provide students with a basis of general knowledge and skills that enable independent critical thinking and promote personal self-growth...it is a continuous process that does not end with the mastery of a specific set of skills in the classroom or future workplace; it involves change not only in knowledge but also in personal beliefs and attitude" [T7, Independent Learning Centre].

Engaging Asian students. It is possible to engage Asian learners, but this means that educators need to adopt different strategies, including having students 
provide anonymous responses (Liu, 2009), using digital devices for voluntary and involuntary activities (Baker Lusk, \& Neuhauser, 2012), having more casual communication with them (Lee, 2009) and possibly assigning students roles and responsibilities (Mckay and Kember, 1997). Nevertheless, students tend to stay with peers from their own common cultural background despite the possibility of positive cross-cultural experiences happening (Montgomery, 2009). Therefore, educators can create opportunities for cross-cultural activities in the curriculum that focus on maximizing talents through inclusivity.

- "In the US, you can raise open questions and the students would not shy away from addressing them in public, while here at CUHK it would be better if you ask them to express their opinions or ideas anonymously" [T12, sociology].

- "I use 'hand-raising' function and 'pick or random' function with an interactive class system and this can enable more effective warming-up interactions" [T2, journalism and communication].

- "Informal conversation. I make efforts to be a person who comes to the classroom first and leaves the classroom last, because these efforts provide me with invaluable opportunities to have an informal conversation with students before and after classroom hours, which helps me to obtain genuine feedback from students" [T11, social work].

- "Students posting questions and peer group responses to one of the questions" [T1, social science].

- "Each group leads class discussion regarding a topic of the assigned week...tracking their participation, and reflecting it on their grade" [T2, journalism and communication].

- "There are a total of eight students in a group, three of whom are discussants to search for literature and books to provide information, two are respondents who criticize information, one student is secretary and is responsible for taking minutes, one student is a presenter, who will be reporting the results on behalf of the group, and one student is an observer, working with the secretary to prepare presentation slides" [T22, nursing].

- "Mixing students in groups [local/international] by alphabetical order in surnames" [T1, social science].

- "Each student to select three most-preferred topics out of six youth problems planned to be covered in the class, and then group students based on their preference...eases invisible tensions that sometimes arise between the two groups of students [Hong Kong vs mainland], suggesting that it is an effective strategy for promoting an 'inclusive' classroom" [T11, social work].

Differentiating undergraduate and postgraduate teaching. New recruits may be assigned to teach both undergraduate and postgraduate courses, and the less experienced teachers may be set tasks that may be perceived as difficult for undergraduates because the foundational knowledge has just been established. On the other hand, experienced educators will create a collegial learning environment 
such that experienced adult learners can provide support to those with limited knowledge or skills (Hodgson \& Chau, 2015).

- "Undergraduate course, I have to present concepts and theories step by step in a very logical way, pay more attention to their application to practical aspects. Graduate-level course, I tend to raise mismatches between theories and facts to motivate the students' discussion" [T19, economics].

- "I have proactive public engagement with partners from international organizations, business sectors, and national think tanks. These networks and experiences allow me to show my undergraduate students how to apply theories taught in class in real-time situations whereas I would connect postgraduate students to related real-world projects" [T20, global studies].

- "Postgraduate students are mature and experienced. I encourage students to share their difficult encounters with clients in their work setting. Through their sharing, students without social work experience can obtain a sense of the practicalities of social work practice" [T13, social work].

\section{Good Teaching Practice}

Experienced faculty members, though new to the university, have already adopted sound pedagogies in their disciplines, while some develop engaging strategies through reflection on actions (Mälkki \& Lindblom-Ylänne, 2012). Among the new recruits, some have had overseas teaching experience, and some reflect on formal and informal student feedback, both positive and negative. Some good teaching practices have emerged among these new recruits:

1. Attend to short attention span:

"Adopt a variation of instruction modality" [T8, social science].

2. Enable development of transferable skills:

"Cultivate students' intellectual capability, have them appreciate the peerreview exercise, such that they gain confidence in expressing opinions" [T14, gender studies].

3. Engage student interest in assessment tasks:

- "I designed some real-world projects, such as how to make a Facebook fan page more popular by using the data students have from Facebook instead of teaching them how to code and how to analyse the data using statistical models" [T23, journalism and communication].

- "Having role play of real estate developers in the public auction process, students are asked to provide a price that is acceptable to them for relocation. The 'auction' function enables them to provide their acceptable price levels without being influenced by their 'neighbours', as the rule of the game is to accept relocation and game over if the majority of residents agree the price" [T24, geography and resource management].

4. Link research and teaching: 
- "I bring my academic research into class....I also strive to incorporate my research on economic disparities and welfare policies into class, which helps students to become aware of the fact that social workers engage in a broad range of activities within multiple types of settings in order to promote social justice" [T11, social work].

- "In the theory-based courses, students are required to complete an academic research paper. The process took them from constructing a theoretical framework to designing a research method, from data collection/analyses to data interpretation, and develop a term paper that is now under review" [T2, journalism and communication].

5. Provide prompt feedback to students:

- "Students can come to seek my comments on the final draft of term papers a few days before deadline without being graded. It encourages those students who want to perfect their work by having a final touchup in light of my feedback as a series of pedagogical dialogues between students and I in order to cater for learning diversity, where guidance and improvement become possible" [T10, gender studies].

6. Pay attention to student feedback:

- "Students welcome more multimedia learning materials and want to have more discussion time between them, particularly for a course with theories that are too abstract to comprehend. I adjust more time for discussion, and provide more multimedia resources" [T4, economics].

- "I replace quizzes with more flexible discussion and writing tools. These tools are designed to encourage careful deliberation, effective communication, and persuasive presentation, with skills of initiating dialogue, conducting debates, and directing discussion flows with respect to others" [T17, gender studies].

\section{Unresolved Challenges}

The biggest drawbacks for non-local new recruits is working in an environment with a language unknown to most of them. This makes it neither possible to access to know resources in the local context, which is traditional Chinese, nor is it possible to communicate freely with local students and the public through the local language. Although they can use materials in English and draw in international examples in their teaching, some local undergraduate students, particularly those less articulate, may not take the opportunity to respond in class or raise questions without concern of embarrassment. Although students may be exposed to international perspectives, they may not be able to act local and think global because there is a shortfall of local connections between different sectors in Hong Kong. Thus, despite new recruits having had an international profile and international collaborators, it takes time to establish a local reputation and connections (Green \& Myatt, 2011).

In addition, the university has had a bilingual policy of university education, and it is not a surprise that some students express the need to use their first 
language to learn and to practise professional knowledge in their teaching evaluations, despite these courses being set as having English as the medium of instruction. Course-end teaching evaluations are marked down because students prefer to be able to learn through their native language (Bodycott \& Walker, 2000).

\section{Conclusion}

Universities will benefit from new international and local recruits because they bring forth new and diverse approaches to teaching in the classroom while maintaining critical reflection and practising effective teaching. This can be a win-win strategy for institutions to learn from international academics about ways to improve existing pedagogy and curriculum practices (Hsieh, 2012). These staff can be a special resource in universities because they provide extensively rich learning opportunities for home learners such that they can build global perspectives and be better prepared for their future careers (Standley, 2015). The majority of students may not have the opportunity to study abroad. Therefore, it is essential for them to be well prepared for intercultural competence and global perspectives through the curriculum so that they can professionally and personally fit into a global economy and be competent locally (Doyle et al., 2010). For local recruits, the extensive teaching and research experience can create abundant opportunities for students to be connected with communities for authentic learning experiences.

Nevertheless, new international recruits may experience a lot of stress with expectations on excellence in teaching and research (Tynan \& Garbett, 2007). As they adjust to the local culture and practices, they may experience dissonance if anticipation is mismatched with reality (Hathaway, 2018). They need to see the complexity of local undergraduate students with English as their second language to adopting academic proficiency in written and oral communications (Kennedy, 2002). As there are many new approaches to teaching Hong Kong students and mainland China students, understanding their differences is necessary. Internationalization at home can connect not only global scholars but also opportunities to have creative and effective pedagogies that can instill student curiosity through their passion to pursue excellence in educating future graduates.

\section{References}

Baker, W. M., Lusk, E. J., \& Neuhauser, K. L. (2012). On the use of cell phones and other electronic devices in the classroom: evidence from a survey of faculty and students. Journal of Education for Business, 87(5), 275-289. https://doi.org/10.1080/08832 323.2011.622814

Beech, N., Macintosh, R., \& Maclean, D. (2010). Dialogues between academics and practitioners: the role of generative dialogic encounters. Organization Studies, 31(910), 1341-1367. https://doi.org/10.1177/0170840610374396 
Bodycott, P., \& Walker, A. (2000). Teaching abroad: lessons learned about inter-cultural understanding for teachers in higher education. Teaching in Higher Education, 5(1), 79-94. https://doi.org/10.1080/135625100114975

Cheng, X. (2000). Asian students' reticence revisited. System, 28(3), 435-46. https://doi. org/10.1016/S0346-251X(00)00015-4.

Choi, P. K. (2010). "Weep for Chinese university": A case study of English hegemony and academic capitalism in higher education in Hong Kong. Journal of Education Policy, 25(2), 233-252. https://doi.org/10.1080/02680930903443886.

De Vita, G., \& Case, P. (2003). Rethinking the internationalisation agenda in UK higher education. Journal of Further and Higher Education, 27(4), 383-398. https://doi.org/ 10.1080/0309877032000128082.

Doyle, S., Gendall, P., Meyer, L., Hoek, J., Tait, C., Mckenzie, L., \& Loorparg, A. (2010). An investigation of factors associated with student participation in study abroad. Journal of Studies in International Education, 14(5), 471-490. https://doi.org/10.11 77/1028315309336032

Dwyer, C.P., Hogan, M.J., \& Stewart, I. (2014). An integrated critical thinking framework for the 21st century. Thinking Skills and Creativity, 12, 43-52. https://doi.org/10.10 16/j.tsc.2013.12.004

Evans, S., \& Morrison, B. (2011). Meeting the challenges of English-medium higher education: the first-year experience in Hong Kong. English for Specific Purposes, 30(3), 198-208. https://doi.org/10.1016/j.esp.2011.01.001.

Foote, K.E., Wei, L., Monk, J., \& Theobold, R. (2008). Foreign-born scholars in US universities: issues, concerns and strategies. Journal of Geography in Higher Education, 32(2), 167-178. https://doi.org/10.1080/03098260701731322

Gao, L., \& Watkins, D. A. (2002). Conceptions of teaching held by school science teachers in P.R. China: identification and cross-cultural comparisons. International Journal of Science Education, 24(1), 61-79. https://doi.org/10.1080/095006901100 66926

Gan, Z. (2009). "Asian learners" re-examined: an empirical study of language learning attitudes, strategies and motivation among mainland Chinese and Hong Kong students. Journal of Multilingual and Multicultural Development, 30(1), 41-58. https://doi.org/10.1080/01434630802307890.

Green, W., \& Myatt, P. (2011). Telling tales: a narrative research study of the experiences of new international academic staff at an Australian university. International Journal for Academic Development, 16(1), 33-44. https://doi.org/10.1080/1360144X.2011. 546219.

Gergen, K.J., McNamee, S., \& Barrett, F. (2001). Toward transformative dialogue. International Journal of Public Administration, 24, 697-707. https://doi-org.easyac cess1.lib.cuhk.edu.hk/10.1081/PAD-100104770.

Halpern, D.F. (1999). Teaching for critical thinking: helping college students develop the skills and dispositions of a critical thinker. New Directions for Teaching and Learning, 80, 69-74. https://doi.org/10.1002/tl.8005.

Hathaway, T. (2018). Negotiating transitions in academic identity: teacher or researcher? In A. Hosein, N. Rao, C.S.-H. Yeh, I.M. Kinchin (eds), Academics' International Teaching Journeys: Personal Narratives of Transitions in Higher Education, pp. 93108. Bloomsbury Publishing. ISBN: HB: 978-1-4742-8977-1.

Hodgson, P., \& Chau, J. (2015). Optimizing interactions to enhance English competence for university students as global learners: A tale of two universities in Hong Kong. International HETL Review, 5(7). https://bit.ly/2SAKriW.

Hodgson, P., Lam, P., \& Chow, C. (2011). Assessment experience of first-year university students: dealing with the unfamiliar. Proceedings of Enhancing Learning 
Experiences in Higher Education: International Conference (digital). https://www. cetl.hku.hk/conference2010/pdf/Hodgson.pdf.

Hsieh, H. (2012). Challenges facing Chinese academic staff in a UK university in terms of language, relationships and culture. Teaching in Higher Education, 17(4), 371-383. http://dx.doi.org/10.1080/13562517.2011.641001.

Jackson, J. (2008). Globalization, internationalization, and short-term stays abroad. International Journal of Intercultural Relations, 32(4), 349-358. https://doi.org/10. 1016/j.ijintrel.2008.04.004

Kennedy, P. (2002). Learning cultures and learning styles: myth-understandings about adult (Hong Kong) Chinese learners. International Journal of Lifelong Education, 21(5), 430-445. https://doi.org/10.1080/02601370210156745.

Klem, A.M., \& Connell, J.P. (2004). Relationships matter: linking teacher support to student engagement and achievement. Journal of School Health, 74(7), 262-273. https://doi.org/10.1111/j.1746-1561.2004.tb08283.x.

Knight, J. (2013). The changing landscape of higher education internationalisation - for better or worse? Perspectives: Policy and Practice in Higher Education, 17(3), 8490. https://doi.org/10.1080/13603108.2012.753957.

Knight, J. (2015). Updated definition of internationalization. International Higher Education, 33, 2-3. https://doi.org/10.6017/ihe.2003.33.7391.

Lanford, M. (2016). Perceptions of higher education reform in Hong Kong: a glocalization perspective. International Journal of Comparative Education and Development, 18(3), 184-204. http://dx.doi.org/10.1108/IJCED-04-2016-0007.

Lee, G. (2009). Speaking up: six Korean students' oral participation in class discussions in US graduate seminars. English for Specific Purposes, 28(3), 142-156. https://doi. org/10.1016/j.esp.2009.01.007.

Lee, H.M. (2014). Hong Kong higher education in the 21 st century. Hong Kong Teachers' Centre Journal, 13, 15-33.

Li, M., \& Bray, M. (2007). Cross-border flows of students for higher education: push-pull factors and motivations of mainland Chinese students in Hong Kong and Macau. Higher Education, 53(6), 791-818. https://doi.org/10.1007/s10734-005-5423-3.

Liu, J. (2009). From learner passive to learner active? The case of Chinese postgraduate students studying marketing in the UK. International Journal of Management Education, 7(2), 33-40.

Lo, W. Y.W., \& Ng, F.S.K. (2013). A critical reflection on internationalization of higher education in Hong Kong: the search for a cosmopolitan alternative. Asia Pacific Journal of Educational Development (APJED), 2(1), 37-46. http://dx.doi.org/10.62 28\%2fAPJED.2013.0201.04.

Mälkki, K., \& Lindblom-Ylänne, S. (2012). From reflection to action? Barriers and bridges between higher education teachers' thoughts and actions. Studies in Higher Education, 37(1), 33-50. https://doi.org/10.1080/03075079.2010.492500.

Maringe, F., \& Sing, N. (2014). Teaching large classes in an increasingly internationalising higher education environment: pedagogical, quality and equity issues. Higher Education, 67(6), 761-782. https://doi.org/10.1007/s10734-013-9710-0.

Maringe, F., \& Jenkins, J. (2015). Stigma, tensions, and apprehension. International Journal of Educational Management, 29(5), 609-626. https://doi.org/10.1108/IJEM04-2014-0049.

Mckay, J., \& Kember, D. (1997). Spoon feeding leads to regurgitation: a better diet can result in more digestible learning outcomes. Higher Education Research \& Development, 16(1), 55-67. https://doi.org/10.1080/0729436970160105. 
Montgomery, C. (2009). A decade of internationalisation: has it influenced students' views of cross-cultural group work at university? Journal of Studies in International Education, 13(2), 256-270. https://doi.org/10.1177/1028315308329790.

Phillips, D., Harris, G., Larson, M., \& Higgins, K. (2009). Trying on-being in-becoming. Four women's journey(s) in feminist poststructural theory. Qualitative Inquiry, 15(9), 1455-1479. http://dx.doi.org/10.1177/1077800409347097.

Robson, S., \& Turner, Y. (2007). "Teaching is a co-learning experience": academics reflecting on learning and teaching in an "internationalized" faculty. Teaching in Higher Education, 12(1), 41-54. https://doi.org/10.1080/13562510601102115.

Shotter, J. (2006). Understanding process from within: an argument for "withness"thinking. Organization Studies, 27(4), 585-604. https://doi.org/10.1177/0170840606 062105.

Soria, K.M., \& Troisi, J. (2014). Internationalization at home alternatives to study abroad: implications for students' development of global, international, and intercultural competencies. Journal of Studies in International Education, 18(3), 261-280. https:// doi.org/10.1177/1028315313496572

Standley, H.J. (2015). International mobility placements enable students and staff in higher education to enhance transversal and employability-related skills. FEMS Microbiology Letters, 362(19), 1-5. https://doi.org/10.1093/femsle/fnv157.

Stone, N. (2006). Internationalising the student learning experience: possible indicators. Journal of Studies in International Education, 10, 409-413. https://doi.org/10.1177/ 1028315306287633

Strayhorn, T. L. (2008). How college students' engagement affects personal and social learning outcomes. Journal of College and Character, 10(2), 1-16. doi: https://doi. org/10.2202/1940-1639.1071.

Thomas, S.L., \& Malau-Aduli, B.S. (2013). New international academics' narratives of cross-cultural transition. International Journal of Higher Education, 2(2), 35-52. https://doi.org/10.5430/ijhe.v2n2p35.

Tavakol, M., \& Dennick, R. (2010). Are Asian international medical students just rote learners? Advances in Health Sciences Education, 15(3), 369-77. https://doi.org/10. 1007/s10459-009-9203-1.

Tynan, B., \& Garbett, D. (2007). Negotiating the university research culture: collaborative voices of new academics. Higher Education Research \& Development, 26(4), 411424. https://doi.org/10.1080/07294360701658617.

Walker, A., \& Dimmock, C. (2000). Mapping the way ahead: leading educational leadership into the globalised world, School Leadership \& Management, 20(2), 227233. https://doi.org/10.1080/13632430050011443.

Whitcomb, J., Borko, H., \& Liston, D. (2009). Growing talent: promising professional development models and practices. Journal of Teacher Education, 60(3), 207-212. https://doi.org/10.1177/0022487109337280.

University Grants Committee (2010). Aspirations for the Higher Education System in Hong Kong: Report of the University Grants Committee. Hong Kong: University Grants Committee.

Yu, B., \& Wright, E. (2017). Academic adaptation amid internationalisation: the challenges for local, mainland Chinese, and international students at Hong Kong's universities. Tertiary Education and Management, 23(4), 347-60. https://doi.org/10. 1080/13583883.2017.1356365. 
